\title{
Erratum to: Cerebral Scedosporium apiospermum infection presenting with intestinal manifestations
}

\author{
D. Lin · Q. Kamili · S. Lai · D. M. Musher · \\ R. Hamill
}

Published online: 3 April 2013

(C) Springer-Verlag Berlin Heidelberg 2013

\section{Erratum to: Infection}

\section{DOI 10.1007/s15010-013-0429-8}

Unfortunately, one of the co-author names has been misspelled in the online published article. The second author name should be changed from K. Qurat-Ul-Ain to Q. Kamili.

The online version of the original article can be found under doi:10.1007/s15010-013-0429-8.

D. Lin $(\bowtie) \cdot$ Q. Kamili · S. Lai · D. M. Musher · R. Hamill

Department of Medicine, Baylor College of Medicine,

1 Baylor Plaza, Houston, TX 77030, USA

e-mail: derekl@bcm.edu

S. Lai

Medical Care Line, Pathology Section, Michael E. DeBakey

Veterans Affairs Medical Center, Houston, TX, USA

D. M. Musher

Department of Molecular Virology and Microbiology,

Baylor College of Medicine, Houston, TX, USA

D. M. Musher · R. Hamill

Medical Care Line, Infectious Disease Section,

Michael E. DeBakey Veterans Affairs Medical Center,

Houston, TX, USA 